\title{
Thermal performance comparison of Rankine cycle, reheat cycle and regenerative cycle with the same initial and final parameters
}

\author{
YarongWang $^{1, *}$, and PeirongWang ${ }^{2}$ \\ ${ }^{1}$ Baoding Electric Power VOC.\&TECH. College, Baoding, Hebei, 071051, China \\ ${ }^{2}$ Hebei Software Institute, Baoding, Hebei, 071000, China
}

\begin{abstract}
The conversion between thermal energy and mechanical energy can be realized through the thermal cycle of working medium in a series of power plants. For the thermodynamic analysis of the thermal cycle, it mainly analyzes the thermal efficiency and steam consumption rate of the cycle to analyze the main factors affecting the thermal efficiency of the cycle, and the measures to improve the thermal efficiency, in order to reduce the fuel consumption and reduce the power generation cost.
\end{abstract}

\section{Introduction}

The steam power cycle is an effective way to convert heat energy into mechanical energy continuously. According to the second law of thermodynamics, the Carnot cycle has the highest thermal efficiency of all cycles in a specific temperature range. However, it is difficult to realize the Carnot cycle when saturated steam is used as working fluid. Besides, the upper limit temperature of the saturated steam, Carnot cycle can only be below its critical temperature, and the lower limit temperature can only be higher than the ambient temperature, so the temperature difference between them is small. Even if the Carnot cycle with saturated steam is realized, its thermal efficiency is not very high.

Therefore, the Rankine cycle has become a basic cycle widely used in modern thermal power plants. Furthermore, with the progress of science and technology, based on the Rankine cycle, there are reheat cycle, regenerative cycle and so on. At present, the actual cycles of steam power plants are very complex, but they are all improved based on the primary cycle. What are the economic differences of these improved steam power cycles? Let us compare them with specific examples.

\section{Comparison}

Example: In a steam power cycle, the initial parameters of fresh steam are $\mathrm{p}_{1}=10 \mathrm{MPa}, \mathrm{t}_{1}=500^{\circ} \mathrm{C}$, The pressure of condenser is $\mathrm{p}_{2}=0.0035 \mathrm{MPa}$. When the fresh steam expands to $\mathrm{p}_{0}=3.5 \mathrm{MPa}$ in the steam turbine, a part of the steam is extracted for regenerative heating, and the rest is sent to the reheater to be heated to $500^{\circ} \mathrm{C}$, and then returns to the steam turbine to do work.

The T-s diagram of this cycle is shown in Figure 1. Because the work consumed in the pump is smaller than that in the circulation, it can be ignored in the calculation.
Therefore, the simplified T-s diagram is shown in Figure 2. The h-s diagram is shown in Figure 3.

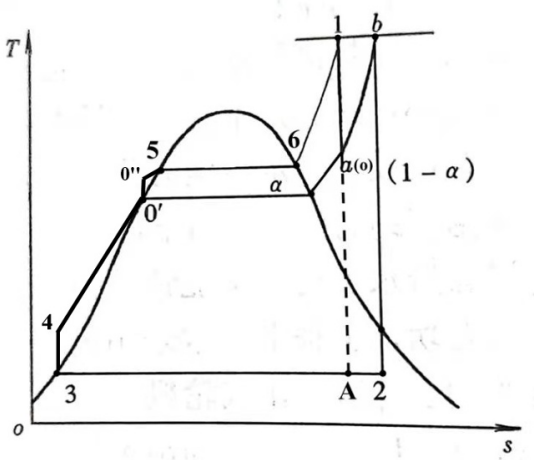

Fig. 1. T-s diagram with one stage regeneration and one reheat cycle.

According to the h-s diagram, the state parameters of the corresponding state points are as follows:

$$
\begin{array}{ll}
h_{1}=3373 & \mathrm{~kJ} / \mathrm{kg} \\
h_{A}=1972 & \mathrm{~kJ} / \mathrm{kg} \\
h_{b}=3453 & \mathrm{~kJ} / \mathrm{kg} \\
h_{2}=2142 & \mathrm{~kJ} / \mathrm{kg} \\
h_{a}=3070 & \mathrm{~kJ} / \mathrm{kg} \\
h_{0}=3070 & \mathrm{~kJ} / \mathrm{kg} \\
t_{s 0}=243 & { }^{\circ} \mathrm{C} \\
t_{s 2}=26.5 & { }^{\circ} \mathrm{C} \\
x_{A}=0.764 & \\
x_{2}=0.833 &
\end{array}
$$




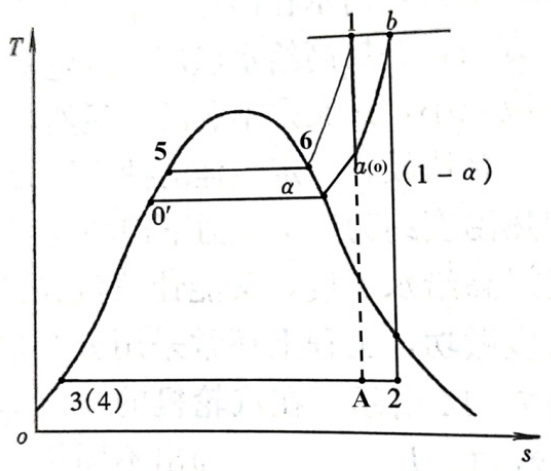

Fig. 2. T-s diagram with one stage regeneration and one reheat cycle.

The enthalpy of saturated water is calculated by saturation temperature, as follows:

$$
\begin{aligned}
h_{2}^{\prime} & =4.1868 \times t_{s 2} \\
& =4.1868 \times 26.5=110.95 \quad \mathrm{~kJ} / \mathrm{kg} \\
h_{0}^{\prime} & =4.1868 \times t_{s 0} \\
& =4.1868 \times 243=1017.39 \quad \mathrm{~kJ} / \mathrm{kg}
\end{aligned}
$$

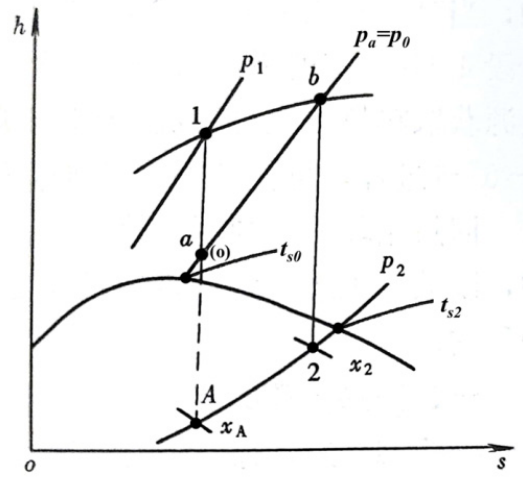

Fig. 3. H-s diagram with one stage regeneration and one reheat cycle.

\subsection{Thermal performance analysis}

\subsubsection{Rankine cycle}

The heat absorption of the cycle is

$$
\begin{aligned}
q_{1} & =h_{1}-h_{4} \\
& \approx h_{1}-h_{2}^{\prime} \\
& =3373-110.95 \\
& =3262.05 \quad \mathrm{~kJ} / \mathrm{kg}
\end{aligned}
$$

The heat release of the cycle is

$$
\begin{aligned}
q_{2} & =h_{A}-h_{3} \\
& =h_{A}-h_{2}^{\prime} \\
& =1972-110.95 \\
& =1861.05 \quad \mathrm{~kJ} / \mathrm{kg}
\end{aligned}
$$

The net work of the cycle is

$$
\begin{aligned}
w_{0} & =\left(h_{1}-h_{A}\right)-\left(h_{4}-h_{3}\right) \\
& \approx h_{1}-h_{A} \\
& =3373-1972 \\
& =1401 \quad \mathrm{~kJ} / \mathrm{kg}
\end{aligned}
$$

The thermal efficiency of the Rankine cycle can be determined by

$$
\begin{aligned}
\eta_{t} & =\frac{h_{1}-h_{A}}{h_{1}-h_{2}^{\prime}} \\
& =\frac{3373-1972}{3373-110.95} \\
& =42.95 \%
\end{aligned}
$$

The steam consumption is

$$
\begin{aligned}
d & =\frac{3600}{h_{1}-h_{A}} \\
& =\frac{3600}{3373-1972} \\
& =2.57 \quad \mathrm{~kg} /(\mathrm{kw} \cdot \mathrm{h})
\end{aligned}
$$

\subsubsection{Reheat cycle}

The heat absorption of the cycle is

$$
\begin{aligned}
q_{1} & =\left(h_{1}-h_{2}^{\prime}\right)+\left(h_{b}-h_{a}\right) \\
& =(3373-110.95)+(3453-3070) \\
& =3645.05 \quad \mathrm{~kJ} / \mathrm{kg}
\end{aligned}
$$

The heat release of the cycle is

$$
\begin{aligned}
q_{2} & =h_{2}-h_{2}^{\prime} \\
& =2142-110.95 \\
& =2031.05 \quad \mathrm{~kJ} / \mathrm{kg}
\end{aligned}
$$

The net work of the cycle is

$$
\begin{aligned}
w_{0} & =\left(h_{1}-h_{a}\right)+\left(h_{b}-h_{2}\right)-\left(h_{4}-h_{3}\right) \\
& =\left(h_{1}-h_{a}\right)+\left(h_{b}-h_{2}\right) \\
& =(3373-3070)+(3453-2143) \\
& =1613 \quad \mathrm{~kJ} / \mathrm{kg}
\end{aligned}
$$




$$
\begin{aligned}
\eta_{t} & =\frac{\left(h_{1}-h_{a}\right)+\left(h_{b}-h_{2}\right)}{\left(h_{1}-h_{2}^{\prime}\right)+\left(h_{b}-h_{a}\right)} \\
& =\frac{(3373-3070)+(3453-2143)}{(3373-110.95)+(3453-3070)} \\
& =44.28 \%
\end{aligned}
$$

The steam consumption is

$$
\begin{aligned}
d & =\frac{3600}{\left(h_{1}-h_{a}\right)+\left(h_{b}-h_{2}\right)} \\
& =\frac{3600}{(3373-3070)+(3453-2142)} \\
& =2.23 \quad \mathrm{~kg} /(\mathrm{kw} \cdot \mathrm{h})
\end{aligned}
$$

\subsubsection{Regenerative cycle}

The mass flow rates are different in different components in regenerative cycle. Determination of the fraction of steam extraction $\alpha$

$\alpha=\frac{h_{0}^{\prime}-h_{2}^{\prime}}{h_{0}-h_{2}^{\prime}}=\frac{1017.39-110.95}{3070-110.95}=0.306$

The heat absorption of the cycle is

$$
\begin{aligned}
q_{1} & =h_{1}-h_{0}^{\prime} \\
& =3373-1017.39 \\
& =2355.61 \quad \mathrm{~kJ} / \mathrm{kg}
\end{aligned}
$$

The heat release of the cycle is

$$
\begin{aligned}
q_{2} & =(1-\alpha)\left(h_{A}-h_{2}^{\prime}\right) \\
& =(1-0.306) \times(1972-110.95) \\
& =1291.57 \quad \mathrm{~kJ} / \mathrm{kg}
\end{aligned}
$$

The net work of the cycle is

$$
\begin{aligned}
w_{0} & =\left(h_{1}-h_{0}\right)+(1-\alpha)\left(h_{0}-h_{A}\right) \\
& =(3373-3070)+(1-0.306) \times(3070-1972) \\
& =1065.01 \quad \mathrm{~kJ} / \mathrm{kg}
\end{aligned}
$$

The thermal efficiency of the Reheat cycle is

$$
\begin{aligned}
\eta_{t} & =\frac{\left(h_{1}-h_{0}\right)+(1-\alpha)\left(h_{0}-h_{A}\right)}{h_{1}-h_{0}^{\prime}} \\
& =\frac{(3373-3070)+(1-0.306) \times(3070-1972)}{3373-1017.39} \\
& =45.21 \%
\end{aligned}
$$

The steam consumption is

$$
\begin{aligned}
d & =\frac{3600}{\left(h_{1}-h_{0}\right)+(1-\alpha)\left(h_{0}-h_{A}\right)} \\
& =\frac{3600}{(3373-3070)+(1-0.306) \times(3070-1972)} \\
& =3.38 \mathrm{~kg} /(\mathrm{kw} \cdot \mathrm{h})
\end{aligned}
$$

\subsubsection{One stage regeneration and one reheat cycle}

The heat absorption of the cycle is

$$
\begin{aligned}
q_{1}= & \left(h_{1}-h_{0}^{\prime}\right)+(1-\alpha)\left(h_{b}-h_{a}\right) \\
& =(3373-1017.39)+(1-0.306) \times(3453-3070) \\
& =2621.41 \quad \mathrm{~kJ} / \mathrm{kg}
\end{aligned}
$$

The heat release of the cycle is

$$
\begin{aligned}
q_{2} & =(1-\alpha)\left(h_{2}-h_{2}^{\prime}\right) \\
& =(1-0.306) \times(2142-110.95) \\
& =1409.55 \quad \mathrm{~kJ} / \mathrm{kg}
\end{aligned}
$$

The net work of the cycle is

$$
\begin{aligned}
w_{0} & =\left(h_{1}-h_{a}\right)+(1-\alpha)\left(h_{b}-h_{2}\right) \\
& =(3373-3070)+(1-0.306) \times(3453-2142) \\
& =1212.83 \quad \mathrm{~kJ} / \mathrm{kg}
\end{aligned}
$$

The thermal efficiency and the steam consumption of the Reheat cycle are

$$
\begin{aligned}
\eta_{t} & =\frac{\left(h_{1}-h_{a}\right)+(1-\alpha)\left(h_{b}-h_{2}\right)}{\left(h_{1}-h_{0}^{\prime}\right)+(1-\alpha)\left(h_{b}-h_{a}\right)} \\
& =\frac{(3373-3070)+(1-0.306) \times(3453-2142)}{(3373-1017.39)+(1-0.306) \times(3453-3070)} \\
& =46.27 \% \\
d= & \frac{3600}{\left(h_{1}-h_{a}\right)+(1-\alpha)\left(h_{b}-h_{2}\right)} \\
& =\frac{3600}{(3373-3070)+(1-0.306) \times(3453-2142)} \\
& =2.97 \mathrm{~kg} /(\mathrm{kw} \cdot \mathrm{h})
\end{aligned}
$$

\subsection{Calculation results}

Under the same initial and final parameters, we calculated the thermal efficiency and steam consumption rate of Rankine cycle, reheat cycle, regenerative cycle, and cycle with one stage regenerative and one reheat, respectively. The results are shown in Table 1,2 and 3.

Table 1. Comparison of calculation results between reheat cycle and Rankine cycle.

\begin{tabular}{|l|c|c|}
\hline $\begin{array}{c}\text { Rankine } \\
\text { cycle }\end{array}$ & reheat cycle \\
\hline
\end{tabular}




\begin{tabular}{|c|c|c|c|}
\hline & & result & $\begin{array}{c}\text { Comparison } \\
\text { with Rankine } \\
\text { cycle }\end{array}$ \\
\hline $\begin{array}{c}\mathrm{q}_{1} \\
\mathrm{~kJ} / \mathrm{kg}\end{array}$ & 3262.05 & 3645.05 & $\uparrow 383$ \\
\hline $\begin{array}{c}\mathrm{q}_{2} \\
\mathrm{~kJ} / \mathrm{kg}\end{array}$ & 1861.05 & 2031.05 & $\uparrow 170$ \\
\hline $\begin{array}{c}\mathrm{w}_{0} \\
\mathrm{~kJ} / \mathrm{kg}\end{array}$ & 1401 & 1613 & $\uparrow 212$ \\
\hline$\eta$ & $42.95 \%$ & $44.28 \%$ & $\uparrow 1.03 \%$ \\
\hline $\mathrm{d}$ & 2.57 & 2.23 & $\downarrow 0.34$ \\
\hline $\mathrm{x}$ & 0.746 & 0.833 & $\uparrow 0.069$ \\
\hline
\end{tabular}

Table 2. Comparison of calculation results between regenerative cycle and Rankine cycle.

\begin{tabular}{|c|c|c|c|}
\hline \multirow{2}{*}{} & \multirow{2}{*}{$\begin{array}{c}\text { Rankine } \\
\text { cycle }\end{array}$} & \multicolumn{2}{|c|}{ regenerative cycle } \\
\cline { 3 - 4 } & result & $\begin{array}{c}\text { Comparison } \\
\text { with Rankine } \\
\text { cycle }\end{array}$ \\
\hline $\begin{array}{c}\mathrm{q}_{1} \\
\mathrm{~kJ} / \mathrm{kg}\end{array}$ & 3262.05 & 2355.61 & $\downarrow 906.44$ \\
\hline $\begin{array}{c}\mathrm{q}_{2} \\
\mathrm{~kJ} / \mathrm{kg}\end{array}$ & 1861.05 & 1291.57 & $\downarrow 569.48$ \\
\hline $\begin{array}{c}\mathrm{w} 0 \\
\mathrm{~kJ} / \mathrm{kg}\end{array}$ & 1401 & 1065.01 & $\downarrow 335.99$ \\
\hline$\eta$ & $42.95 \%$ & $45.21 \%$ & $\uparrow 1.96 \%$ \\
\hline $\mathrm{d}$ & 2.57 & 3.38 & $\uparrow 0.81$ \\
\hline $\mathrm{x}$ & 0.746 & 0.746 & $\rightarrow$ \\
\hline
\end{tabular}

Table 3. Comparison of calculation results between one stage regeneration and one reheat cycle and Rankine cycle.

\begin{tabular}{|c|c|c|c|}
\hline \multirow{2}{*}{$\begin{array}{c}\text { Rankine } \\
\text { cycle }\end{array}$} & \multicolumn{2}{|c|}{$\begin{array}{c}\text { one stage regeneration and one } \\
\text { reheat cycle }\end{array}$} \\
\cline { 3 - 4 } & result & $\begin{array}{c}\text { Comparison with } \\
\text { Rankine cycle }\end{array}$ \\
\hline $\begin{array}{c}\mathrm{q}_{1} \\
\mathrm{~kJ} / \mathrm{kg}\end{array}$ & 3262.05 & 2621.41 & $\downarrow 640.64$ \\
\hline $\begin{array}{c}\mathrm{q}_{2} \\
\mathrm{~kJ} / \mathrm{kg}\end{array}$ & 1861.05 & 1409.55 & $\downarrow 451.5$ \\
\hline $\begin{array}{c}\mathrm{w} 0 \\
\mathrm{~kJ} / \mathrm{kg}\end{array}$ & 1401 & 1212.83 & $\downarrow 188.17$ \\
\hline$\eta$ & $42.95 \%$ & $46.27 \%$ & $\uparrow 3.02 \%$ \\
\hline $\mathrm{d}$ & 2.57 & 2.97 & $\uparrow 0.4$ \\
\hline $\mathrm{x}$ & 0.746 & 0.833 & $\uparrow 0.069$ \\
\hline
\end{tabular}

\section{Conclusion}

It can be seen that the intermediate reheat can significantly improve the steam turbine exhaust dryness, improve the thermal efficiency of the cycle, and reduce the steam consumption rate. Compared with the Rankine cycle with the same parameters, the thermal efficiency of the regenerative cycle is improved. Only because of the steam extraction, the work per kilogram of steam in the turbine is reduced. To keep the power unchanged, it is necessary to increase the steam intake, thus increasing the steam consumption rate of the cycle.

With the continuous improvement of parameters and power of steam turbine generator units in thermal power plants, more and more units adopt regenerative and steam reheat at the same time.

As shown in the table above, this improves the cycle thermal efficiency, exhaust dryness, and reduces the impact on steam consumption rate. By comparing the above calculation results, we can see the necessity of improving the steam power cycle more intuitively. Especially for our students in higher vocational colleges, we can better understand the improvement of economic indicators, due to the improvement of the steam power cycle.

Of course, with the adoption of the reheat cycle and regenerative cycle, a series of thermal equipment need to be added to make the whole system more complex, and the investment cost of equipment also needs to increase. This needs to be measured comprehensively and taken as a whole. Besides, the calculation results also confirm that the thermal efficiency of the cycle is generally less than $50 \%$ even if reheating and regenerative methods are used.

\section{References}

1. Jing, Z.H. (2009) Thermal Engineering, China Electric Power Press, Beijing.

2. Shang, Y.Q. (2007) Engineering Thermodynamics. China Electric Power Press, Beijing.

3. Tong, J.G., Wang, P.Y., Su, Y.K.(2008) Thermal engineering. Shanghai Jiaotong University Press.

4. Zhao, L, Engineering Thermodynamics (A Bilingual Textbook) (2012), China Building Industry Press, Beijing.

5. Zhu, M.S., Liu, Y., Lin, Z.Z., Peng, X.F. (2011) Engineering Thermodynamics. Tsinghua university press, Beijing.

6. Xu, Y.P., Ke, X.Y. (2012) Thermal Engineering. China Electric Power Press, Beijing.

7. Cheng, G.T., Wang, Y.Z. (2007) Engineering Thermodynamics (Second Edition). Beijing University of Technology Press, Beijing.

8. Chen, Z.H. (2009) Basic Thermal Engineering, China Electric Power Press, Beijing.

9. Shen, W.D., Geng, T.J. (2007) Engineering Thermodynamics, Higher Education Press, Beijing. 